\title{
Ingenieros, hacendados y
}

empresarios en conflicto

por el aprovechamiento

del agua del río Lerma en

Jalisco a fines del siglo XIX

\section{y principios del xx}

\section{Rebeca Vanesa García Corzo ${ }^{1}$ revagarcia@gmail.com}

Engineers, Ranchers and Businessmen

Conflicts over Water Control and Usage

in the Lerma River in Jalisco in the Late

19th and Early 20th Centuries

\section{Resumen}

El trabajo es un acercamiento a la dinámica establecida por algunos ingenieros, hacendados y empresarios en su pugna por apropiarse parcialmente del agua del río Lerma a su paso por tierras de Jalisco. Se observan algunas prácticas de apropiación y estrategias de uso y consumo del agua en un momento clave del desarrollo industrial del estado, y de modificación de paradigma tecnológico: la introducción de la electricidad con fuerza hidráulica. Se observa cómo la transición de la pequeña a la gran hidráulica dio oportunidad de desarrollar las mejores habilidades de los ingenieros-hacendados.

Palabras clave: río Lerma, Jalisco, hacendados, ingenieros, empresarios, electricidad.

\section{Abstract}

This work is an approach to the dynamics set among some engineers, landowners and businessmen in their struggle to partially appropriate the water of Lerma River that crossed their land in Jalisco. The article is focused on the practices of appropriation and usage strategies as well as on water consumption in a key moment for the industrial development of Jalisco, and the modification of the current technological paradigm at that time: the introduction of electricity with hydropower. The text allows to observe how the transition from small to large hydro technology provided an opportunity to develop the best skills of the engineers-ranchers.

Key words: Lerma River, ranchers, engineers, businessmen, water conflicts. Universidad de Guadalajara, Centro Universitario de Los Lagos, México. Enrique Díaz de León 1144, Paseos de La Montaña, 47460, Lagos de Moreno, Jalisco, México.

Letras Históricas / Número 15 / Otoño 2016-invierno 2017 / México / pp. 145-177 / ISSN: 2007-1140 
Este trabajo se concentra en un estudio de caso ubicado temporalmente entre 1890 y 1906, cuando las polémicas leyes sobre la posesión del agua dieron lugar a un vacío y a la defensa de intereses particulares por encima de los intereses de grupo de los terratenientes, y antes de la creación de la Caja de Préstamos para Obras de Irrigación, institución que permitiría la concreción de los esfuerzos del Estado encaminados a la expansión del regadío.

En las páginas siguientes se presentan las acciones de un subconjunto de esos actores, el de los ingenieros dueños de haciendas o el de hacendados con título de ingenieros (según quien sea el observador) y empresarios que, aprovechando los conocimientos tecnológicos de sus profesiones, la posesión de la tierra y los vínculos cercanos con Porfirio Díaz y ciertos funcionarios, intervinieron en conflictos de poder donde se muestran las tensiones internas del grupo hegemónico jalisciense porfiriano en medio del proceso de modernización del campo. Con ello en mente, el objetivo de estas líneas es llevar a cabo un acercamiento a la dinámica de estos personajes entre sí y con otros empresarios en su pugna por apropiarse parcialmente del agua del cauce del río Lerma ${ }^{2}$ al paso por sus tierras.

Para reconstruir este proceso se han utilizado fuentes documentales, bibliográficas y hemerográficas de diferentes acervos en la ciudad de México y los estados de Michoacán y Jalisco. La investigación se hizo sobre todo en el Archivo General de la Nación, en el Archivo Histórico del Agua, en el Archivo Histórico de Jalisco, en los fondos especiales de la Biblioteca Pública del estado de Jalisco, en la biblioteca del Colegio de Michoacán, así como en la Hemeroteca Nacional de México y la Hemeroteca Histórica de Jalisco.

A través de las consultas ha sido posible aproximarse al tema de las prácticas de apropiación y las estrategias de uso del agua en un momento clave del desarrollo industrial del estado de Jalisco y de modificación del paradigma tecnológico: la introducción de la electricidad con fuerza hidráulica. Esto vino a sumarse a

la posibilidad de construir presas más altas, resistentes y baratas gracias a los nuevos diseños y materiales de construcción (concreto de diversos tipos), lo mismo que grandes canales de conducción o de Querétaro, Guanajuato y Michoacán hasta llegar al lago de Chapala, atraviesa Ocotlán y el valle de Cuitzeo hacia Poncitlán, lugar donde llegaba a formar "el salto cuyo nombre le da este pueblo, y en donde la corriente se precipita a 1 metro y 95 centímetros de altura por entre rocas de basalto", Matute, Proyecto de canalización. 
desagüe, así como la aparición del motor de combustión interna y de la bomba eléctrica, dispositivos fundamentales para extraer grandes volúmenes de aguas del subsuelo. ${ }^{3}$

La historiografía sobre el agua en México es un campo muy rico, cuya producción más abundante se ubica a partir de la década de 1980 y abarca múltiples perspectivas espaciales y temporales. Los estudios se centran en el ámbito urbano y en el rural con problemáticas regionales y locales que incluyen la legislación, la aplicación de proyectos concretos (abastecimiento urbano, irrigación, industrialización, apropiación y desecación de cauces), los conflictos suscitados en el ámbito político y social en el proceso, así como las consecuencias ambientales, entre otras. A ello se agrega la recopilación y publicación de fuentes que invita a profundizar en determinados temas.

Respecto de los trabajos relativos a la irrigación durante el porfiriato, Kroeber $^{4}$ y Aboites ${ }^{5}$ han abordado la legislación y el papel del Estado en el desarrollo de la distribución y los usos del agua en el país. Ellos han destacado el proceso seguido por el gobierno central para apoderarse del control y manejo del agua en previsión de los beneficios que pudiera obtener de su explotación agrícola e industrial por empresas nacionales y extranjeras ${ }^{6}{ }^{6}$ así como la diversificación de estas regulaciones a favor de múltiples industrias provechosas para los grandes propietarios. ${ }^{7}$

Abundando en el tema, Tortolero, a través del juego de escalas enfocado en las haciendas de Chalco, Morelos y Amecameca, ha demostrado la importancia de las innovaciones científico-tecnológicas -que incluían la infraestructura hidráulica- en la modernización de las haciendas, al igual que Valerio lo ha hecho para Jalisco. ${ }^{8}$ Estos trabajos han contradicho la tesis aceptada tradicionalmente por la historiografía posrevolucionaria acerca del atraso generalizado de esas propiedades que preconizara Molina Enríquez. ${ }^{9}$ Además, mediante el trabajo inverso, de la irrigación a la desecación, Tortolero demostró cómo el gobierno cedió espacio a los concesionarios y a los hacendados-empresarios para

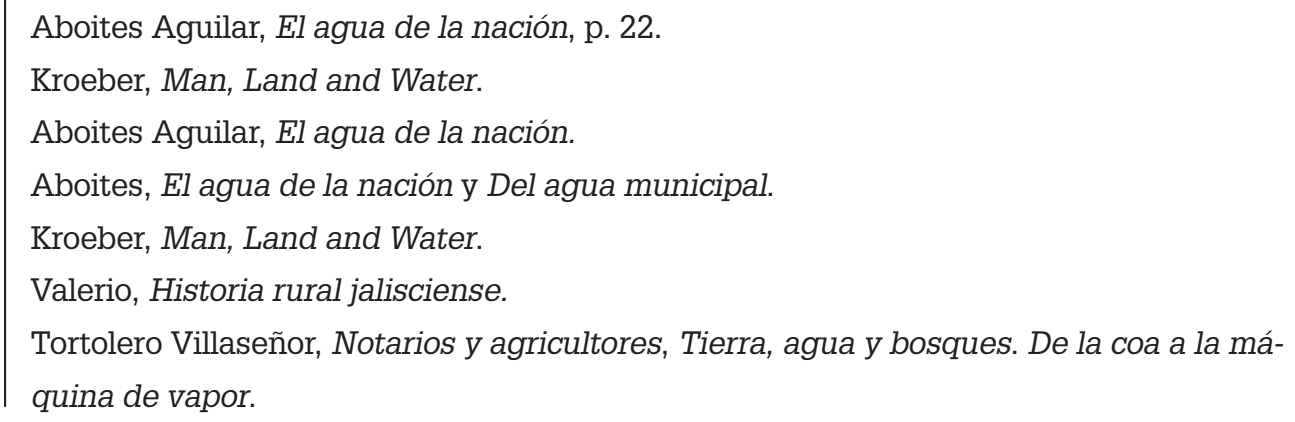


el ejercicio de su control. Sánchez Rodríguez ${ }^{10}$ ha retomado también el proceso de centralización estatal del manejo de los recursos hidráulicos, en esta ocasión en el Bajío, incorporando el método comparativo con lo ocurrido en España y Estados Unidos, lo que le llevó a afirmar que "se trata de un proceso global que favorecía la intervención estatal en la economía y, por supuesto, en la agricultura de riego". ${ }^{11}$

A propósito de la cuenca Lerma-Chapala en el porfiriato se ha destacado el papel de los diferentes actores sociales involucrados en los conflictos generados por las grandes explotaciones y la intención de desecar los terrenos para la explotación agrícola, lo que hizo la familia Cuesta Gallardo en la ciénega de Chapala en $1905 .{ }^{12}$

En medio de tal producción sobre el Lerma, y retomando la centralización gubernamental del control del agua mencionada párrafos atrás, Wester $^{13}$ ha ubicado en ese momento los orígenes de la "hidrocracia" (burocracia hidráulica) mexicana. Este grupo, que surgió como tal después de la revolución, llevó a cabo deliberadamente la sobreexplotación de la cuenca mediante sistemas de diques y de irrigación, así como modificaciones del propio lago de Chapala en lo que se podría entender como la prosecución de su misión hidráulica. ${ }^{14}$

10

12 siguientes: "Características hidrológicas e historia hidráulica de la Ciénega de Chapala", "Arrendatarios y prestamistas en la Ciénega de Chapala durante el Porfiriato", "Guadalajara y Chapala: historia de una relación regional. Siglo XIX y principios del xx", "La desecación de la Ciénega de Chapala y las comunidades indígenas: el triunfo de la modernización en la época porfiriana", "Transformación del paisaje industrial y urbano en el occidente de México: los proyectos de la familia Cuesta Gallardo durante el Porfiriato". (her, "Capturing the waters". Wester escribió su tesis doctoral, Shedding the Waters: Institutional Change and Water Control in the Lerma-Chapala Basin, Mexico (Wageningen Agricultural University, Países Bajos), sobre la misión hidráulica en la Cuenca Lerma Chapala, un estudio de larga duración. Derivado de la tesis, en 2009 publicó el artículo "Capturing the Waters". Ha llevado a cabo un estudio de mediana duración en el que retoma el concepto de burocracia hidráulica (hidrocracia) que condujo a la centralización del desarrollo del agua y la sobreexplotación en la cuenca Lerma-Chapala entre 1876 y 1976.

14 El concepto es elaborado a partir de los trabajos de Worster (1985) y Reisner (1993). Wester, "Capturing the Waters", pp. 9-10. La misión hidráulica partía de la fuerte con- 
El proceso que se trata en las presentes páginas ha sido considerado por Wester como parte inicial de esa misión hidráulica, cuando se trasladó el control del agua del ámbito local al gobierno federal. Su hipótesis es que esta forma oligárquica de desarrollo de recursos hídricos, idea que retoma de Aboites, conllevó que el gobierno federal no hubiera construido obras hídricas, sino que más bien apoyó a un grupo de hacendados y compañías extranjeras con préstamos y concesiones para llevarlas a cabo. No obstante, la autonomía local y el control sobre el agua permanecieron fuertes durante el porfiriato, y la incursión del gobierno federal fue selectiva. ${ }^{15}$

Con tales antecedentes, es el interés de este artículo contribuir al conocimiento de los actores sociales que participaron en la realización y operación de los proyectos, con nombres y apellidos, así como a través de su perfil y de sus relaciones, elementos susceptibles de ser documentados, según señalara Boehm hace años. ${ }^{16}$ La participación de personajes pertenecientes a las elites agrícolas, económicas y tecnológicas de la región en el proceso de uso y aprovechamiento del agua del río Lerma en Jalisco contribuyó a transformar el paradigma tecnohidráulico de la región.

De hecho, el estudio de las elites ${ }^{17}$ cuenta con una amplia tradición histórico-sociológica que ha buscado entender y definir estos grupos a los que, de manera genérica, se ha caracterizado por la posesión de fortuna y cultura (saber, educación). ${ }^{18}$ En ese entramado, el subconjunto de las elites agrícolas ha sido objeto de reflexión particular en el ámbito

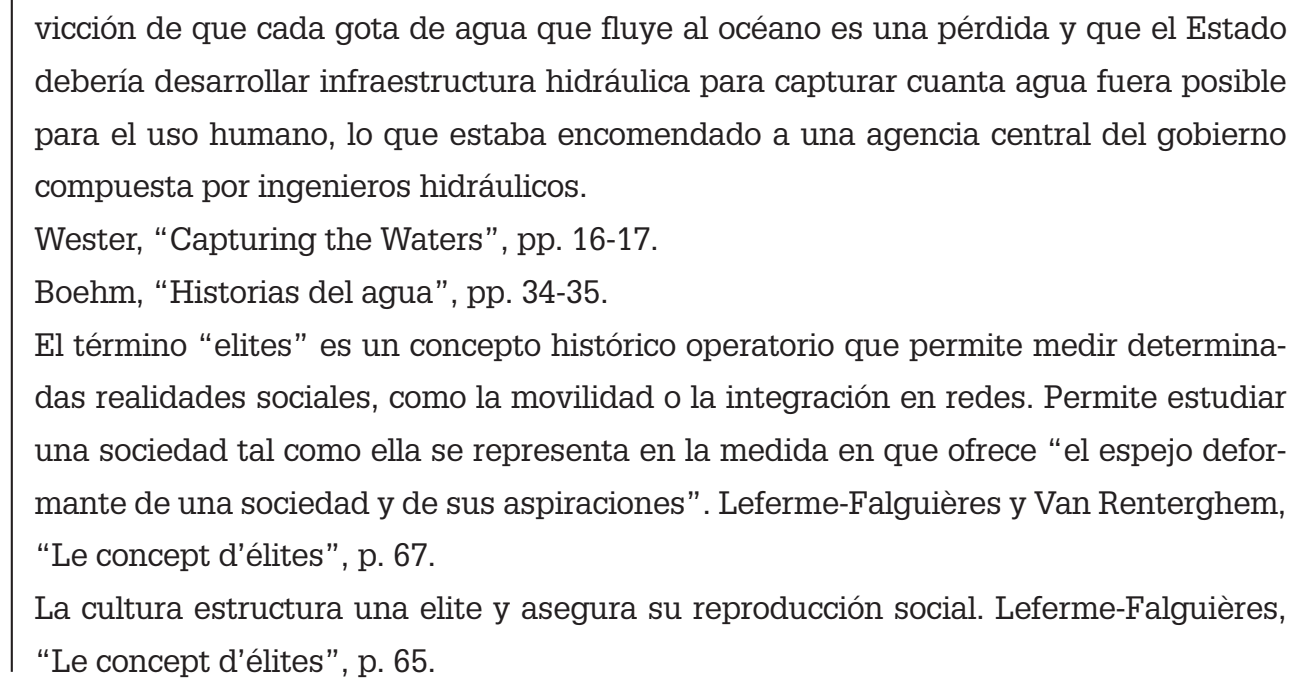


europeo de la mano de autores como Vivien ${ }^{19}$ y Sarrazin, ${ }^{20}$ que han creado interesantes grupos internacionales de trabajo.

Los personajes aquí presentados en sus diversas facetas se insertan en ese conjunto debido a ciertas características, tales como la difusa oposición entre la ciudad y el campo, la posesión de dos o tres residencias distribuidas entre esos espacios, el impacto de influencias personales e institucionales ligadas con empresas, o su pertenencia a sociedades comerciales y agrícolas, ${ }^{21}$ al igual que su compromiso con la modernización científico-tecnológica de sus propiedades. ${ }^{22}$

En ese sentido, es particularmente relevante el papel de las conexiones sociales ${ }^{23}$ en el desarrollo y la facilitación de tales actividades. Esas conexiones desempeñan un papel fundamental al producirse y conservarse a través de nexos familiares, societarios, de transacciones económicas y de la propia posesión de la tierra. En ese marco se desenvolvieron las acciones producto de la pertenencia a un grupo social privilegiado de poseedores de un capital económico y cultural que les proveyó de las herramientas para soportar técnicamente y en forma prolongada los reclamos sobre el agua ante las autoridades federales.

19 Vivier, Élites et progrès agricole. En ese volumen, en el apartado sobre los grandes propietarios y el progreso agrícola, Tortolero, siguiendo la temática de trabajos anteriores, presenta una reflexión sobre las diferentes medidas de modernización implementadas por los hacendados de Chalco en un proceso de adaptación a la presión del mercado y lo compara con otros estados del país; Carmona retoma el tema para el caso español al estudiar el interés y los esfuerzos de las grandes familias aristocráticas en la modernización de sus propiedades agrícolas, a pesar de su dispersión y amplitud, así como ciertos casos de nuevos aristócratas y notables locales. Tortolero, "Les grandes exploitations mexicaines", pp. 227-254, y Carmona, "Aristocratie foncière", pp. 259-277.

Sarrazin, Les élites agricoles et rurales.

Véanse Vivier, “Quelles élites?", y Sarrazin, "Introduction", pp. 9-18.

El caso concreto de Manuel García de Quevedo y su desenvolvimiento como científico, hacendado y funcionario en la modernización de la ciudad y el campo jalisciense ha sido trabajado en Biografía del ingeniero jalisciense Manuel García de Quevedo y Zubieta (1854-1924), Memoria DEA, doctorado en Historia y Análisis Social, métodos y análisis socio-cultural, Universidad de Oviedo, 2010. Debido a la multiplicidad de sus actividades, se le ha considerado un mediador cultural entre los diferentes grupos a los que perteneció.

Se ha optado por hablar de redes sociales cualitativas en sentido laxo para ejemplificar la existencia de tales vínculos a través de la relación con el dominio del agua. 


\section{Ingeniería, agricultura y agua}

El siglo XIX fue un periodo clave en el cambio de la relación del hombre con el agua, en el que surgió lo que Jean Robert denomina "el concepto ingenieril del agua". ${ }^{24}$ Se develó el misterio de su composición y descomposición en una formulación química básica y simple, $\mathrm{H}_{2} \mathrm{O},{ }^{25}$ que se sumó a los desarrollos tecnológicos para su explotación.

Los ingenieros jaliscienses decimonónicos compartían la visión de que la riqueza del país consistía en el dominio tecnológico de los conflictivos recursos naturales mexicanos, y concretamente del agua. La utilidad de este grupo durante el porfiriato les generó prestigio y facilitó su aceptación en la sociedad por ser los poseedores del conocimiento técnico necesario para desarrollar el proyecto modernizador mexicano. ${ }^{26} \mathrm{~A}$ través de sus trabajos se plasmó la dinámica del subsistema hidráulico en Jalisco a fines del siglo XIX, la dicotomía campo-ciudad, así como la coexistencia y la transición de la tradición a la modernidad. Fue un proceso en el que el dominio de la teoría y la maestría de la práctica ocupaban un lugar fundamental, en ocasiones una por encima de la otra, a tal grado que se afirmaría que "en la hidrología, más que en ninguna otra ciencia aplicada, vale más que el mejor cálculo el resultado de una experiencia". ${ }^{27}$

Efectivamente, la hidrología resultó ser fundamental para la vía extensiva de explotación agrícola que se implementó en Guadalajara y su región. Esto supuso la generación de un frágil equilibrio en el que las actividades económicas primaban sobre las ambientales. En el proceso, el control y la manipulación del agua fueron elementos cruciales en la intensificación agrícola y la transformación del paisaje.

24

Robert, "Las aguas arquetípicas", p. 41.

Los momentos decisivos se dan a partir de 1783, cuando se llevó a cabo la primera síntesis del agua a partir del oxígeno y el hidrógeno -Lavoisier y Laplace-; a esto se sumó el descubrimiento -por Cavendish- de que el agua era la asociación del hidrógeno y del oxígeno que permitió a los ingleses Anthony Carlisle (1768-1840) y William Nicholson (1753-1815) en 1800 producir un experimento de hidrólisis a través del cual se pudo formular químicamente el agua.

Participaban en los diferentes planes de crecimiento urbano y del estado, en el trazado de límites con otros estados, en la redefinición de espacios tras las leyes de desamortización de la década de 1850, en la construcción de líneas férreas, en el reconocimiento de minerales, en estudios para la prevención de desastres naturales como erupciones volcánicas e inundaciones, en la industrialización del país y un largo etcétera.

García de Quevedo, “Conferencia popular sobre irrigación”, p. 67. 
Las medidas gubernamentales que favorecieron esa vía fueron la privatización de la propiedad a través de la política de colonización y de deslindes, ${ }^{28}$ la formación de una Dirección General de Estadística (1883) para hacer un catastro de propiedades y un censo agrícola, ${ }^{29}$ la definición de los derechos de propiedad en materia de aguas, ${ }^{30}$ el establecimiento de la Caja de Préstamos para Obras de Irrigación, ${ }^{31}$ las bases para la extensión del ferrocarril que generó un gran mercado interno, la creación de servicios agronómicos y centros de enseñanza e investigación, la difusión de nuevas tecnologías, de sistemas de patentes, y la celebración, a partir de 1893, de la Exposición Agrícola de Coyoacán. ${ }^{32}$

En 1902, congruentes con estas políticas llegadas del centro, los ingenieros jaliscienses agrupados en la Escuela Libre de Ingenieros de Guadalajara, consideraban la irrigación como factor de gran relevancia para el progreso de la agricultura nacional. ${ }^{33}$ Para fomentarla recomendaban acciones básicas como la construcción de presas, porque retener el agua de lluvia en ellas era "enriquecer a nuestra Patria; y quien haga esto debe ser considerado como benefactor público". Ése era uno de los medios de sacar a la agricultura mexicana (rama principal de la riqueza pública) de $\mathrm{su}$ "pretendido atraso". ${ }^{34}$ Sin embargo, las obras de irrigación no eran de

28

Véanse al respecto la Ley sobre Deslinde de Terrenos y Colonización de 1883, la Ley sobre Ocupación y Enajenación de Terrenos Baldíos de 1894 y su derogación parcial en 1902, entre otras.

29

Su fin principal era compilar, clasificar y publicar periódicamente estadísticas comparativas del ramo económico a través de censos tanto del ámbito poblacional como de catastro de la propiedad urbana, rústica y minera a efecto de conocer la riqueza del país. Las bases legales de la medición catastral se encontraban en la Ley Especial de Catastro y su Reglamento para el Territorio Nacional, en la que se contemplaba la medición, planos municipales y la propiedad particular. él ser mediador, sobre todo a partir de la creación en 1897 de una oficina en la Secretaría de Fomento encargada del tema.

31 
fácil realización debido a los inconvenientes que los agricultores encontraban a la hora de ejecutarlas, como la ausencia de capital de explotación, la reevaluación hacendaria de una finca tras la mínima modificación y la ausencia de instrucción de la mayoría de la clase agrícola.

Eran estos ingenieros integrantes del grupo que desarrolló la cartografía decimonónica a través de su servicio como funcionarios de los diferentes niveles de gobierno. En su papel de ingenieros del estado, de la ciudad, integrantes de comisiones delimitadoras o de reevaluación de propiedades, se involucraron en la reconstrucción y la representación cartográfica del país y en un nuevo sentido de apropiación de los recursos de tierra y agua. Muchos de ellos estaban ligados con las familias terratenientes de Jalisco por lazos familiares o clientelares. Eran miembros de las elites agrícolas, lo que los convertía en elementos de gran relevancia en la definición del espacio y el funcionamiento de las relaciones de poder. ${ }^{35}$

El desarrollo de obras de irrigación a varias escalas surgió como reflejo de la noción de progreso asociado a la tecnología para el control de los recursos naturales. Aparte del agua manejada por grupos como comunidades indígenas y campesinas, los hacendados y las empresas la gestionaban en forma individual. Eran éstos los que consideraban los recursos naturales, tan ponderados durante la primera mitad del siglo, como una carga más que una ventaja, porque impedían el libre tránsito por el país en razón de factores como la ausencia de ríos navegables y la existencia de cadenas montañosas. La mayor crítica que se les hizo fue que impidieran la existencia y el sostenimiento de agua para la producción agrícola. ${ }^{36}$

En las últimas décadas de la centuria la pugna entre los grupos sociales y las instituciones por el control del agua para sus diversos usos en la agricultura, la industria y el abasto a localidades urbanas y rurales se intensificó debido a múltiples factores. El año de 1890 fue, de acuerdo con las ideas de Andrés Molina Enríquez que Luis Aboites retoma, ${ }^{37}$ un momento de inflexión respecto de la concepción del agua

la intensiva, lo que implicaba el sostenimiento de prácticas agrícolas coloniales y poca inversión en la modernización del campo.

35 omisión (y de L. Cabrera) que ha permeado en la mayor parte de la historiografía contemporánea sobre el agua. Tortolero, Notarios y agricultores, pp. 26 y 27. De hecho, Tortolero parte de la aplicación del método de Molina Enríquez centrándose en tres de sus 
en el país. Se produjo una transición del "agua local", con aprovechamientos a pequeña escala y actores locales o regionales que se disputaban su uso y recurrían a acuerdos consuetudinarios o notariales, ${ }^{38}$ hacia el "agua nacional", lo que implicó una ruptura en las prácticas y las relaciones de los diferentes actores del proceso. Fue entonces cuando los empresarios y el gobierno adquirieron renovado interés en el recurso en un "movimiento social [que] descansaba en un cambio tecnológico revolucionario en la escala de los aprovechamientos del líquido". ${ }^{39}$

En ese marco, entre 1880 y 1900 hay constancia de tres tipos de actividades de ingeniería hidráulica íntimamente relacionadas, desarrolladas por los ingenieros en el campo jalisciense: en primer lugar, las de irrigación, útiles para incrementar la cantidad y la variedad de cultivos que alimentaban a la ciudad y que, con la llegada del ferrocarril, se llevarían a mercados nacionales e internacionales; en segundo lugar, el aprovechamiento de los cauces para la navegación de embarcaciones mercantes que transportarían los productos jaliscienses; en tercer lugar, el aprovechamiento del agua como fuerza motriz para la instalación de centrales hidroeléctricas de pequeña capacidad, útiles en diferentes actividades de las haciendas y la generación de electricidad para iluminar la ciudad. Eran labores de pequeña y gran hidráulica.

El desarrollo de la pequeña hidráulica se dio con procesos como la construcción de presas, "embalses de almacenamiento, de energía hidroeléctrica, redes de canales de distribución de agua y amplias actuaciones de drenaje y bonificación". ${ }^{40}$ Estas prácticas eran bastante rudimentarias debido a que originalmente comprendían presas construidas con piedras, hierbas y estacas a las que se sumaban cajas de acequias. ${ }^{41}$ En las cajas se incluían templadores (ladrones o vertedores) que eran aberturas en la pared lateral que daba al río por las que "una vez cubiertas las cantidades de agua designadas a cada caja, los sobrantes regresaran al río con el fin de que pasaran a las cajas inferiores". ${ }^{42}$

problemas en la región Chalco-Amecameca (propiedad, crédito e irrigación) partiendo del juego de escalas e insertándose en el análisis micro.

38

39

40

41

(est estrecha perpendicular a ella, en la que había orificios de distintos tamaños a través de los cuales pasaba el agua. Podía haber cajas principales (medidoras) y secundarias (repartidoras) que subdividían el agua entre dos o más propiedades.

42 
En las haciendas de Jalisco las presas eran las obras más habituales, y una parte importante de su alimentación era el agua de lluvia que caía abundantemente en los meses de verano. La necesidad de controlar el agua disponible en las diferentes presas y acequias hizo que se practicara la medición en cada una, con una escala métrica y la instalación de pluviómetros para registrar las lluvias y la altura diaria de nivel. Un interesante ejemplo es el de la hacienda de Atequiza, donde bajo la administración de Manuel Capetillo ${ }^{43}$ se estableció un sistema de canales de derivación del río para regar la propiedad y fertilizar una zona de cuatro mil hectáreas.

Retomando el caso de la irrigación y la postura oficial como gremio adoptada a través de las páginas del Boletín de la Sociedad de Ingenieros, trasladar las medidas del ámbito discursivo a la praxis, institucional ${ }^{44} \mathrm{e}$ individualmente, permitió que los ingenieros se convirtieran en mediadores socioculturales a distintos niveles: ingenieros-hacendados-gobierno local-gobierno central. Las prácticas derivadas de sus conocimientos, aplicadas en apoyo de la política gubernamental y en su propio beneficio como empresarios, les permitieron ser actores del dinamismo de la comunidad de hacendados jaliscienses finisecular decimonónica. En este artículo se ofrece un estudio de caso que ejemplifica esta situación a través de los conflictos surgidos por el control del agua en el Lerma-Santiago, cuyos actores principales fueron los ingenieros jaliscienses hermanos García de Quevedo, el ingeniero, político y propietario Manuel Cuesta Gallardo y el empresario proveniente de la ciudad de México José María Bermejillo.

\section{Los actores}

Manuel García de Quevedo (1854-1924) nació en el seno de una familia que llegó de Cantabria en el siglo XVIII y fue dueña de la hacienda de Toluquilla, en la Nueva Galicia. En 1873 hizo el examen de ingeniero hidromensor y agrimensor en el Instituto de Ciencias de Jalisco. Hermano mayor de una familia numerosa, tras la muerte de su padre en 1879 quedó como tutor de sus hermanos menores y, tras la repartición de la herencia y la compra de las partes de sus hermanos, fue dueño de la próspera ha-

${ }_{43}$ En 1876 los dueños de Atequiza (Francisca Reisch viuda de Gallardo y su hijo Vicente Gallardo) celebraron una compañía por siete años con Manuel Capetillo (dueño de la hacienda de Buenavista) para que la dirigiera y administrara. Capetillo recibiría el 25 por ciento de las ganancias.

44 En la Sociedad y la Escuela de Ingenieros de Guadalajara y la Cámara Agrícola Jalisciense. 
cienda de Arroyo de Enmedio, en Tonalá, donde llevó a cabo labores de aclimatación y experimentación de cultivos y la construcción de dos presas y seis bordos para el aprovechamiento del agua en el riego. Fue profesor de la Escuela de Ingenieros y de la Escuela Libre de Ingenieros de Guadalajara, munícipe en diversas ocasiones del Ayuntamiento de Guadalajara e ingeniero de la ciudad. Fue presidente de la Cámara Agrícola Jalisciense, de la Cámara de Comercio de Guadalajara y miembro de la Sociedad de Ingenieros de Jalisco, además de editor y autor de artículos aparecidos en el Boletín de esa sociedad y en el de la Cámara Agrícola. Como ingeniero llevó a cabo labores de delimitación de tierras, de irrigación del río Duero en Zamora (1897), representó a Jalisco en diversas exposiciones nacionales e internacionales y fue además presidente de la Junta Local de Bosques.

Su hermano Miguel Ángel G. de Quevedo y Zubieta (1862-1946; más conocido como el apóstol del árbol) quedó tras la muerte de su padre a cargo de su tío paterno Bernabé, en Bayonne. En la Universidad de Burdeos recibió el grado de bachiller en ciencias en 1883; estudió ingeniería civil en la Escuela Politécnica de París, con especialización en ingeniería hidráulica, y se diplomó en 1887, año en que volvió a México. Se le recuerda por grandes labores como presidente de la Junta Central de Bosques que publicó la Revista Forestal, la creación de parques en la ciudad de México y de los viveros de Coyoacán, aprovechando su cercanía con José Yves Limantour y, tras la revolución, la conversión del Desierto de los Leones en el primer parque nacional protegido del país. Además, participó en congresos nacionales e internacionales sobre temas diversos. Como ingeniero civil, llevó a cabo múltiples actividades como la supervisión de la fábrica de tejidos e hilados de San Ildefonso (1895), y entre 1896 y 1904 estuvo a cargo de la construcción de la fábrica de cigarros El Buen Tono, propiedad del empresario francés Ernesto Pugibet, así como de la iglesia del mismo nombre en 1912. A ello se sumó, entre sus numerosas actividades, haber sido consultor para la construcción de ferrocarriles en el Valle de México, así como los negocios que desarrolló junto con su hermano Manuel y de los que se ocupa este artículo.

Manuel Cuesta Gallardo (nacido en 1873), aparte de ser un relevante político porfirista y dueño de la hacienda de Atequiza, también había estudiado ingeniería. La hacienda era propiedad de su familia, y cuando se incorporó al negocio familiar entre 1896 y 1900 consiguió que la hacienda incrementara en cinco mil hectáreas las tierras de riego con la construcción de un acueducto para canalizar el agua de la laguna de Cajititlán a través del arroyo de los Sabinos. En 1898, asociado con otros empresarios y políticos como el cuñado de Díaz, Lorenzo Elízaga, fundó una compa- 
ñía para canalizar y aprovechar en riego las aguas de la laguna de la Magdalena. ${ }^{45}$ Estableció el primer molino de cilindros que funcionó en el estado, la primera fábrica de alcohol de maíz que transformó en alcohol de remolacha en 1894, y mostró sus diversos logros en las exposiciones regionales, nacionales e internacionales. Además fue gobernador del estado en el periodo final del mandato de Díaz, y diputado federal. También era miembro de la Cámara Agrícola Jalisciense e introdujo el lirio y la carpa en 1905 a Chapala.

José María Bermejillo e Ibarra (1839-1904) era oriundo de Balmaseda (Vizcaya). Llegó a México a mediados del siglo XIX y se estableció en la ciudad de México. En 1861 se casó con María Dolores Martínez Negrete y Alba, de Guadalajara, y para 1886 tenía 1150 acciones del Banco Mercantil Mexicano, 1000 del Mexicano y 5344 del Nacional de México. En 1889 se comenzó a edificar la fábrica textil Río Grande, inaugurada el 17 de mayo de 1896, junto con la colonia industrial de El Salto, conocida actualmente como Las Cuadras. Dicha fábrica fue construida en los terrenos aledaños a la hacienda de Jesús María por las familias Bermejillo y Martínez Negrete. Su edificación estuvo a cargo del ingeniero Alberto Robles Gil. Entre los cultivos más destacados de la propiedad estuvo el trigo, para el cual se estableció un molino harinero. Robles Gil, además de ser ingeniero activo, fue sucesor de Cuesta Gallardo en el gobierno del estado de Jalisco en 1911; un fenómeno, el de los ingenieros gobernadores, inaugurado por Mariano Bárcena en 1889.

\section{El posicionamiento de los actores: intereses gubernamentales y de los ingenieros-hacendados y empresarios}

La proliferación de los trabajos de irrigación tuvo varios factores detonantes; uno de los más importantes fue que la regulación de los usos del agua fuera una de las prioridades del gobierno mexicano en materia de agricultura, particularmente durante el porfiriato, cuando se produjo un proceso paulatino de centralización del poder en manos del gobierno federal. ${ }^{46}$

En ese sentido, resultó fundamental la Ley sobre Vías Generales de Comunicación del 5 de junio de 1888. Al Ejecutivo federal le correspondía la vigilancia, la policía y la facultad de reglamentar su uso público y pri-

45 Boehm, “Transformación del paisaje industrial”, pp. 163-164.

46 El 14 de agosto de 1886 se emitió una circular sobre las caídas de agua de las haciendas de beneficio de minerales, que debían ser denunciadas junto con la construcción de los beneficios. Legislación federal, 1897-1898, p. 423. 
vado. ${ }^{47} \mathrm{~A}$ partir de entonces, tanto el río Grande como el lago de Chapala serían su responsabilidad, y todos los asuntos relativos a ellos deberían ser revisados y autorizados por el gobierno federal.

A partir de la instalación de las primeras plantas hidroeléctricas en México ${ }^{48}$ se expidió el decreto del 6 de junio de 1894 que fue complementario de la ley anterior y permitió al poder Ejecutivo el otorgamiento de concesiones a particulares para el aprovechamiento de aguas en riegos y como potencia industrial. A los concesionarios se les exentaba de impuestos durante cinco años y se les otorgaba el derecho de ocupar gratuitamente los terrenos baldíos y nacionales para el paso de los canales destinados a la construcción de presas o diques y para la formación de depósitos. Las tarifas eléctricas estarían sujetas a la aprobación del gobierno federal.

En apoyo de la legislación estatal, en Jalisco se expidió el decreto 696 del 19 de septiembre de 1895, conocido como Ley de aguas de Jalisco, a través del cual se especificaron los límites jurisdiccionales sobre el agua en el estado, se establecieron los trámites necesarios para la obtención de concesiones de agua y se permitió únicamente al gobernador otorgar concesiones y aprobar las tarifas. ${ }^{49}$

Por si hubiera ambigüedad en la materia, el 17 de diciembre de 1896 se expidió otro decreto que reafirmó la jurisdicción federal sobre el control de los recursos hidráulicos, de tal forma que se transfirieron a la Secretaría de Fomento y Colonización todas las funciones relacionadas con el otorgamiento de concesiones, franquicias y permisos para la generación de energía eléctrica. Sólo a ella le correspondía la interpretación exclusiva e inapelable de la legislación en la materia. ${ }^{50}$

47

Incluyeron en esas vías los mares territoriales, los esteros y lagunas de las playas de la República, los canales construidos por la Federación o con auxilio del erario nacional, los lagos y ríos interiores si fueran navegables o flotables, así como los lagos y ríos de cualquier clase y en toda su extensión que sirvieran de límites a la República o a dos o más estados. en el último tercio del siglo XIX. Los usos fueron inicialmente mineros e industriales. La fuerza sobrante se empleó para iluminar las ciudades y poblados cercanos a las industrias. De la Garza, "La integración de la industria eléctrica", p. 354. "Decreto sobre el aprovechamiento de las aguas del estado, haciendo concesiones a particulares para la construcción de presas, canales o depósitos". Guadalajara, septiembre 19 de 1895. Publicado el 24 de septiembre por Luis C. Curiel. Colección de los decretos, circulares y órdenes de los poderes legislativo y ejecutivo del estado de Jalisco.

50 Valerio, "Empresas, tranvías y alumbrado público", p. 235. 
Este marco legal permitió que se multiplicaran las inversiones en obras de irrigación para la agricultura, pero también el aprovechamiento de la fuerza motriz del caudal del río Santiago para la introducción del alumbrado y los tranvías eléctricos en Guadalajara. A fines del siglo XIX y principios del xx las empresas que efectuaron esas labores se fusionaron paulatinamente hasta conformar un importante monopolio encargado de dotar a la ciudad de alumbrado público y de la totalidad del servicio de tranvías a base de energía eléctrica, la Compañía Hidroeléctrica e Irrigadora de Chapala, S.A. (1907). Era la producción de la gran infraestructura hidráulica frente a la pequeña de las presas y los canales anteriores.

La hacienda de Arroyo de Enmedio tenía una ubicación privilegiada, al ser paso obligado para los viajeros que iban de Guadalajara a San Pedro y a la región de los Altos de Jalisco, al igual que lindaba al norte y al oriente con la barranca por la que corre el río Grande. ${ }^{51}$ Esta situación marcó una relación especial del propietario, el ingeniero Manuel García de Quevedo, y su hermano el ingeniero Miguel Ángel de Quevedo, con la cuenca, el lago y los dueños de haciendas ribereñas. Según sus propias afirmaciones, su carácter incluía la "honorabilidad y recta conciencia profesional", ${ }^{52}$ seguramente generada por su origen, pues eran hijos de un rico propietario terrateniente, pero también gracias a la experiencia laboral, lo que facilitaría su intervención en las vías de comunicación aledañas y el aprovechamiento del agua, bien para riego, bien como fuerza motriz de las industrias establecidas.

En ese entonces la utilidad de Chapala era contemplada desde dos perspectivas simultáneamente: el interés en la desecación de terrenos para su uso agrícola y el aprovechamiento de sus aguas para establecer compañías de navegación.

Respecto del primer punto, en décadas previas había habido algunos proyectos rechazados para desecar el "mar chapálico" y acondicionar para la navegación los ríos Lerma y Duero, entre ellos el de Manuel de J. Olasagarre, Mariano Otero y Samuel L. Trant (1842); ${ }^{53}$ el presentado a Maximiliano para alzar una ciudad llamada Miramar en medio de llanuras desaguadas (1864) y el de Ignacio Castellanos, dueño de dos haciendas en la parte septentrional de la ciénega de Chapala, quien sometió al pre-

\footnotetext{
51 En total, esta cuenca tiene una extensión de $122850 \mathrm{~km}^{2}$, de los cuales corresponden 40551 al Lerma desde su nacimiento hasta Chapala, 9370 a la propia cuenca de Chapala y 72929 al Santiago desde Chapala hasta la desembocadura en el océano Pacífico. Boehm, "Características hidrológicas", p. 89.

52 Quevedo, La cuestión del lago de Chapala, p. 44.

53 Alamán, Diccionario universal de historia y geografía, p. 668.
} 
sidente Juárez (1867) una propuesta para convertirla en tierras agrícolas. Tras consultar a los habitantes ribereños, la última se rechazó ante el temor de producir la desertificación del área. ${ }^{54}$

El segundo proyecto, la navegación, fue más afortunado. En 1866 Maximiliano autorizó el establecimiento de una línea de buques de vapor en el lago de Chapala y en el río Grande, una compañía anónima para el establecimiento y cuidado de los buques, barcas de pasajeros y remolcar embarcaciones de carga ${ }^{55}$. El presidente de la Junta Directiva fue el padre de los dos ingenieros, José Valente García de Quevedo.

Pasada la intervención francesa, el vapor Libertad navegaba en Chapala, aunque su recorrido era bastante limitado, sólo de 50 leguas. Así lo señalaba el ingeniero Juan B. Matute en 1871, cuando propuso la canalización de una parte del río Grande para hacer navegable una porción mayor de su curso, particularmente en el recorrido hasta Juanacatlán, donde había 15 leguas que se harían practicables con una canalización "muy fácil", de media legua. ${ }^{56}$ Esto no se llevó a cabo, a pesar de los felices augurios del ingeniero.

Durante el porfiriato el interés en la ciénega y en el lago de Chapala se incrementó considerablemente. Si la navegación y la desecación tenían fines agroindustriales, comenzó a aparecer la visión empresarial de Chapala como centro turístico que rivalizaba con San Pedro Tlaquepaque en atracción para las elites tapatías. Esto se vio beneficiado por la presencia del presidente Porfirio Díaz y su familia, que a lo largo de nueve años fueron de vacaciones a la villa de Chapala. ${ }^{57}$

El tramo del río Grande de la cascada del Salto de Juanacatlán también tenía sus virtudes. La belleza física del lugar provocó el deseo de establecer una línea de ferrocarril de tracción animal entre Guadalajara y El Salto (1871). Proyectado por Juan Bautista Matute, pasaría por San Pedro, Arroyo de Enmedio, El Castillo y, finalmente, llegaría a Juanacatlán. El proceso resultaría útil a J. Valente Quevedo, pues atravesaba dos de sus propiedades (El Castillo y Arroyo), aunque también implicaría sacrificio de su parte al serle expropiados los terrenos necesarios para la instalación.

En 1893 el transporte a Juanacatlán ya estaba bien establecido y se dividía en dos fases que se recorrían en hora y media. En la primera, un tren de pasajeros salía todos los días de Guadalajara a las nueve de la maña-

\footnotetext{
54 Boehm, "Características hidrológicas", p. 94.

55 Compañía Anónima de Navegación, p. 13.

56 Matute, Proyecto de canalización, p. 5.

57 Boehm, "Características hidrológicas", p. 96.
} 
na, recorría 24 kilómetros y llegaba hasta la estación del Castillo, situada en la hacienda del mismo nombre y que pertenecía a José María Bermejillo desde $1877 .^{58} \mathrm{La}$ segunda fase consistía en continuar el trayecto en "un amplio tranvía tirado por cuatro mulas" que recorría 7 kilómetros. ${ }^{59}$

El último tramo había sido de reciente creación por un contrato celebrado entre Bermejillo y el gobierno del estado. Se puso al servicio del público en octubre de 1889, aunque no estuviera acabado, con las recomendaciones dadas por el ingeniero del estado para que "al terminar los terraplenes se deje en buen estado el paso a nivel en el cruzamiento del camino de Juanacatlán". ${ }^{60}$ Curiosamente, ese ingeniero fue Manuel García de Quevedo, que se encontraba de nuevo con Bermejillo y sus negocios, aunque no sería la última ocasión.

Era esa impresionante cascada, "el Niágara mexicano", magnífica; tenía unos ciento veinte metros de elevación y originalmente surtía fuerza motriz para el molino de trigo de la hacienda de Jesús María, propiedad de Dolores Martínez Negrete, hija del connotado empresario español Francisco Martínez Negrete ${ }^{61}$ y que se había casado con Bermejillo. La propiedad familiar aumentó cuando éste adquirió la hacienda de El Castillo. En esa zona, un hermano de Dolores, Francisco Martínez Negrete, compró parte de los terrenos de Jesús María a su hermana para establecer la fábrica textil de Río Grande, a partir de 1896, así como su colonia, "el último gran proyecto industrial del siglo XIX en Jalisco". ${ }^{62}$

En cuanto a Bermejillo, debe mencionarse la diversificación de sus actividades empresariales en torno al aprovechamiento del agua, puesto que estuvo involucrado en la introducción de la electricidad en Guadalajara en 1884. En 1892, como representante de la Compañía de Luz Eléctrica de Guadalajara, ${ }^{63}$ celebró un contrato con el ayuntamiento ${ }^{64}$ que implicó la generalización de la electricidad para el alumbrado público en las calles y el palacio de gobierno ${ }^{65}$ hasta que la ciudad se iluminó por completo. La energía provino del aprovechamiento de la cascada del Salto

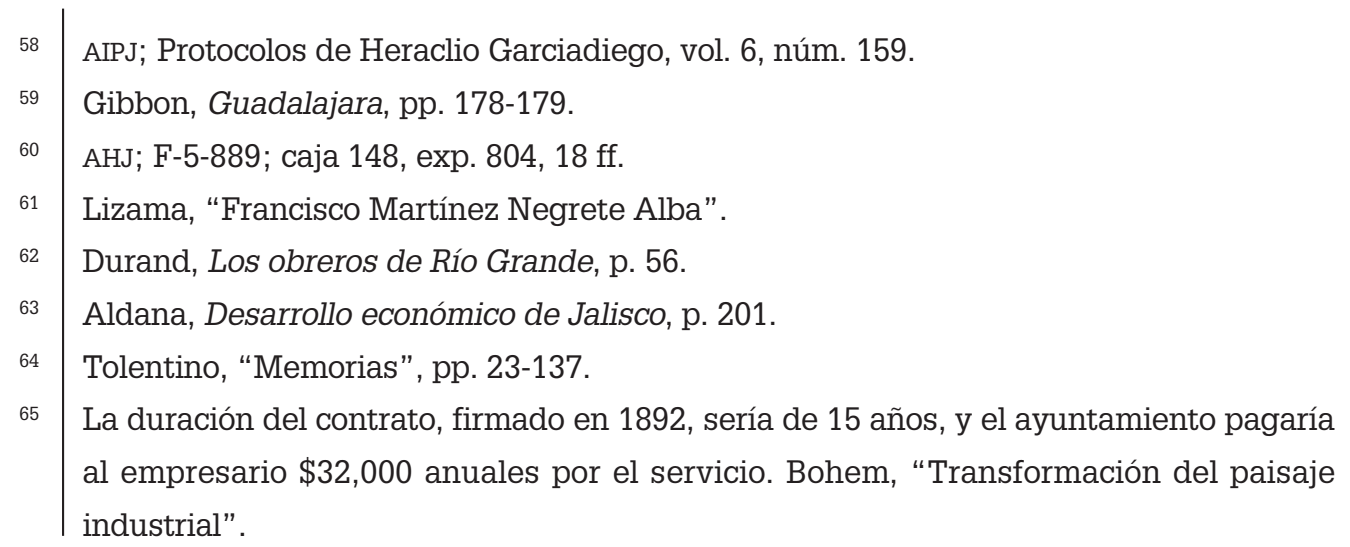


de Juanacatlán, donde se instaló una planta eléctrica que fue inaugurada en 1893 e iluminó la urbe "con luz eléctrica superior a toda la de otras ciudades del país". ${ }^{66}$

Como se puede observar, la legislación estatal y federal benefició a Bermejillo que, paulatinamente, se hizo un lugar en el ámbito de los hacendados al adquirir una propiedad a los García de Quevedo, así como al casarse con una terrateniente encumbrada, y en el de los empresarios con los ambiciosos proyectos hidroeléctricos. También se ha notado que el interés de los García de Quevedo por capitalizar el flujo del río y las aguas de Chapala databa de bastante tiempo atrás, y su capacidad como ingenieros les permitíría proponer proyectos y optimizar los resultados.

\section{Primer conflicto: el control de la fuerza motriz y la Compañía Hidráulica Mexicana}

Antecedente de la Compañía Hidráulica e Irrigadora de Chapala, fundada en 1909 por Manuel Cuesta Gallardo, fue la Compañía Hidráulica Mexicana, una aventura emprendida por los hermanos García de Quevedo y en la que tanto José María Bermejillo como Cuesta Gallardo tuvieron cierto protagonismo.

Aprovechando el contrato para iluminar la ciudad de Guadalajara, así como el decreto del 6 de junio de 1894, José María Bermejillo solicitó en agosto de 1895 la concesión de toda la corriente que pasara por el Salto de Juanacatlán, con la finalidad de emplearla como fuerza motriz. ${ }^{67}$

Esta situación dio pie a una serie de documentos dirigidos a la Secretaría de Fomento en oposición a la solicitud de Bermejillo, entre ellos el del empresario español Manuel Fernández del Valle y el de los hermanos García de Quevedo. En su escrito fechado el 24 de octubre de 1895, los últimos indicaban que habían solicitado la concesión de las aguas no aprovechadas en un tramo del río de Santiago en que estaba com-

66 El 24 de junio de 1893, en una ceremonia fastuosa en que el gobernador Luis C. Curiel y 150 invitados más participaron del banquete. En El Mercurio Occidental se afirmaba que la máquina generadora de energía eléctrica era la segunda en su género, ya que sólo en Inglaterra había otra más potente. La del Salto podía alimentar 7500 lámparas de 16 bujías cada una, muestra de su fuerza y sus dimensiones; Gibbon, Guadalajara, p. 189. El periodista jalisciense Manuel Caballero confirmó esa opinión de Gibbon; Iguíniz, Guadalajara a través de los tiempos, p. 107. AHA, México, Aprovechamientos superficiales; caja 4616; exp. 61449; Secretaría de Fomento, Colonización e Industria; Dirección de Aguas; Depto. de Concesiones; Estado de Jalisco; Municipio de Tonalá. 
prendido dicho salto o cascada y en cuya ribera contigua de la margen derecha Manuel era dueño de terrenos regados desde hacía muchos años por las aguas del río. Además, en la zona había otros ribereños, clientes de ambos hermanos, cuyos proyectos de aprovechamiento se verían perjudicados, ${ }^{68}$ lo que quedó demostrado con la carta de oposición que envió Pedro Navarro, uno de esos clientes de los Quevedo, "a pesar de que no mencionó mi nombre en la solicitud". ${ }^{69}$

El resultado de ese intercambio epistolar, tras la consiguiente investigación para dar seguimiento al trámite iniciado por los García de Quevedo el 7 de julio, un mes antes que Bermejillo, fue que los hermanos firmaron un contrato con la Secretaría de Fomento el 2 de diciembre del mismo año, para que

por sí o por la Compañía que organizaren, ejecutasen las obras hidráulicas necesarias para aprovechar como fuerza motriz, hasta cinco metros cúbicos de agua por segundo de las caídas de agua y rápidos del río Grande de Santiago que se encuentran en el trayecto de dos kilómetros contados río abajo desde el puente de Tololotlán. ${ }^{70}$

El contrato especificaba que debían emplear la fuerza hidráulica para establecimientos industriales o para producir energía eléctrica para la ciudad de Guadalajara u otra población. Esto suponía una clara competencia con la empresa de Bermejillo, lo que quedó demostrado al repetir éste su demanda a lo largo de los años siguientes, alegando como causa la gran sequía que aquejaba a la región y el bajo caudal del río Grande, de tal forma que "por primera vez desde hace muchísimos años no alcanza a satisfacer las necesidades de las concesiones y mercedes otorgadas a diversas fincas".

Eso hacía "indispensable" la ejecución en el Salto de Juanacatlán de ciertas obras que permitieran utilizarlo todo. Se accedió a ello, aunque indicando que debería ser de carácter temporal. Fue entonces que el ingeniero Miguel Ángel de Quevedo, el empresario y experto en su papel, redactó una nota "sobre el consumo de agua que hacen las instalaciones de aprovechamiento de fuerza en la margen izquierda del río Grande de Santiago en Juanacatlán" ${ }^{71}$ en la que se afirmaba que, no obstante el uso

68

69

70

71 AHA, Aprovechamientos Superficiales, caja 4616, exp. 61450c Secretaría de Fomento, 
del agua para el molino de trigo, el riego de las tierras, la fábrica de hilados y electricidad para Guadalajara, la concesión otorgada previamente era suficiente, porque no se empleaba la fuerza simultáneamente. ${ }^{72}$ Pero sus esfuerzos resultaron inútiles.

Mientras tanto, y para poner en marcha el proyecto de aprovechamiento de la fuerza motriz de 1895, el 17 de marzo de 1896 se constituyó la sociedad anónima denominada La Hidráulica Mexicana, a la que los hermanos Quevedo aportaron el contrato celebrado en 1895 con la Secretaría de Fomento. Para fortalecer la compañía, Manuel vendió a La Hidráulica (1ํำ de agosto de 1896) el terreno denominado Garita Vieja y el rancho de La Cuchara, ambos en la margen derecha del río Santiago, opuesta a las tierras de Bermejillo y que incorporaría la toma de agua en los rápidos de Tololotlán. ${ }^{73}$

Dando continuidad a los proyectos de navegabilidad del río, ese mismo año los hermanos celebraron el 31 de marzo de 1896 otro contrato con la Secretaría de Fomento para realizar obras de mejoramiento en los ríos Lerma, Grande o de Santiago y Duero, para facilitar la navegación desde La Piedad (Michoacán) hasta el lago de Chapala. ${ }^{74}$ Se unieron entonces los dos intereses en el aprovechamiento del caudal del río Grande, la fuerza motriz y la navegación.

Los planos de ambos proyectos -las caídas de agua del río Santiago desde Tololotlán y el proyecto de navegación de los ríos Lerma, Duero y Santiago, unidos al lago de Chapala-fueron presentados por Manuel, en su papel de ingeniero, en la Exposición Universal de París de $1900^{75} \mathrm{como}$ adelantos tecnológicos de gran valía.

Colonización e Industria, Serie Dirección de Aguas, Subserie Depto. de Concesiones, Estado de Jalisco, Municipio de Tonalá, Localidad Hacienda del Castillo, Corriente río Grande o Santiago.

72

73

75 AHJ, F-7-899, caja 303, legajo 36, exp. 708. ciones y Obras Públicas. Colonización e Industria, Dirección de Aguas, Depto. de Concesiones, Jalisco. AHA; Aprovechamientos superficiales, caja 3212, exp. 44203, Secretaría de Fomento, Serie Dirección de Aguas, Subserie Quinta División. Zona Tres, Estado de Jalisco, Plano realizado por M. G. de Quevedo del tramo del canal construido por la Compañía Hidráulica Mexicana, 1897. Escala 1:500; AHA, Aprovechamientos superficiales, caja 3260, exp. 44771, Secretaría de Fomento, Serie Dirección General De Aguas. AHA, Aprovechamientos superficiales, caja 4616, exp. 61442, Secretaría de Comunica-

.7-899, caja 303, legajo 36, exp. 708.

Letras Históricas / Número 15 / Otoño 2016-invierno 2017 / México / pp. 145-177 / ISSN: 2007-1140 
Los problemas de sequía y de escasez de agua en el río Grande continuaban, y tanto Bermejillo ${ }^{76}$ como los Quevedo pretendieron ampliar la concesión otorgada, lo que dio pie a la oposición de ambos lados y un acuerdo parcial entre las partes, ${ }^{77}$ a las que hubo que sumar una tercera, la de Gabriel Cruz, propietario de La Aurora. ${ }^{78}$

Finalmente, Bermejillo, La Hidráulica Mexicana y los hermanos Quevedo celebraron una transacción por la que La Hidráulica se desistió de unas solicitudes que había hecho y se conformó con otras que había presentado Bermejillo para aprovechar el agua del río Santiago, arriba del puente de Tololotlán; asimismo, se estableció a favor de la hacienda del Castillo una servidumbre de abrevadero de ganado con la senda que llevaba al aguaje, situado en los terrenos de La Hidráulica.

A cambio, Bermejillo, en representación de su esposa (hay que recordar que ella era la dueña del Salto de Juanacatlán), se comprometió a retirar las oposiciones a las solicitudes de La Hidráulica para aprovechar las aguas del río Santiago y, para que pudiera ensanchar el canal que

76 Un año después, en 1897, José María Bermejillo escribía (el 27 de marzo) que "la escasez de agua en el río Grande o de Santiago ha sido este año tan considerable que, para asegurar la marcha de la planta de luz eléctrica establecida por mí en el Salto de Juanacatlán, ha sido necesario formar pequeños bordos de césped o terrón para evitar que durante el día el agua se pierda inútilmente y aprovecharla durante la noche a fin de poner en movimiento la referida planta eléctrica, que provee al alumbrado público de la ciudad de Guadalajara". Como el propietario de La Aurora iba a hacer uso del metro y medio cúbico que se le había concedido, ahora Bermejillo solicitaba la realización de la obra para evitar que cesara el movimiento de la planta eléctrica. AHA, Aprovechamientos superficiales, caja 4616, exp. 61450.

AHA, Aprovechamientos superficiales, caja 4623, exp. 61579, Secretaría de Agricultura y Fomento, Serie Dirección de Aguas, Subserie Depto. de Concesiones. Sec. Tramitación. Quinta División.

1897-1904. Gabriel B. Cruz solicita una concesión para aprovechar la corriente generando fuerza motriz. Oposición de Hidráulica Mexicana, S. A. (AHA, Aprovechamientos superficiales, caja 4615, exp. 61438 y 61439) 1899. Emilio Velasco, director de la Compañía Hidráulica Mexicana S.A. solicita que se amplíe la concesión de 1895 para aprovechar mayor volumen de agua del río Santiago. Oposición de Dolores Martínez Negrete y de Gabriel B. Cruz. Llegan a un acuerdo con los Quevedo para el aprovechamiento adecuado. (AHA, Aprovechamientos superficiales, caja 4619, exp. 61494) 1899. Autorización de la concesión a Dolores Martínez Negrete de Bermejillo para realizar obra en El Salto de Juanacatlán para derivar energía en producción de electricidad. Oposición de la Compañía Hidráulica Mexicana, S.A. (AHA, Aprovechamientos superficiales, caja 4615, exp. 61440). 
había construido por la concesión original, cedió a la compañía la franja de terreno necesaria, no mayor de quince metros de ancho a lo largo del canal, que formaba parte de los terrenos del rancho de San Fernando. ${ }^{79}$

Las obras originales de las que se hace mención fueron realizadas por Manuel García de Quevedo para La Hidráulica Mexicana, y consistieron en: ${ }^{80}$

1. Presa construida a inmediaciones del puente de Tololotlán. La cortina tenía una forma curvilínea de sección trapezoidal y una longitud de doscientos veintisiete metros. ${ }^{81}$

2. Canal a la margen izquierda del río, de unos mil seiscientos metros de longitud y una anchura de tres a tres y medio metros. Comenzaba en la presa y terminaba en la barranca de La Cuchara, donde se obtenía una caída de unos setenta metros de altura. ${ }^{82}$

3. Tres compuertas de regularización de un metro veintidós centímetros de anchura por un metro diez centímetros de altura y otra compuerta de escape a un costado del canal.

Todo lo anterior fue vendido íntegramente el 15 de noviembre de 1902 por La Hidráulica Mexicana a Manuel Cuesta Gallardo, dueño de la hacienda de Atequiza, caracterizada por estar a la vanguardia de los adelantos tecnológicos en materia de generación eléctrica desde 1888 y presumida ampliamente en el incipiente cine de la época. Se incluyó el derecho para gestionar y obtener las concesiones que había solicitado La Hidráulica para aprovechar las aguas del río Grande como fuerza motriz en un trayecto de cuatro kilómetros debajo de donde termina-

79

80

81

\footnotetext{
de la Compañía Hidráulica. Seguía una extensión como de novecientos metros por el terreno de San Fernando Buenavista, propiedad de José María Bermejillo, y concluía en La Cuchara, propiedad de la Compañía. Anexo al canal había un camino para su vigilancia y servicio.

Todo el terreno destinado al canal y al camino anexo, con longitud de mil seiscientos metros desde las presas hasta la caída y una anchura de veintisiete metros, lindaba del lado del río (oriente) con el potrero de Buenavista del rancho de San Fernando, y con terrenos de La Cuchara de La Compañía Hidráulica Mexicana. Del lado opuesto (poniente) en el extremo meridional, lindaba con el río y terreno de la Garita Vieja, propiedad de la compañía, y en el extremo del norte con La Cuchara.
}

82 
ba la concesión de 2 de diciembre de 1895 y para que se ampliara esa concesión. ${ }^{83}$

El intermediario de la transacción, y parte interesada, fue el propio Manuel, a quien se le compensó, además de por su "intervención y agencias" en el negocio, por "servicios profesionales prestados al señor Manuel Cuesta Gallardo". A cambio, se le favoreció con la potencia hidráulica de los saltos de Tololotlán y de la caída, conforme a la concesión de 2 de diciembre de 1895 que pertenecía a Cuesta, y cinco mil pesos con sus réditos al seis por ciento por haber puesto en explotación la concesión que Cuesta había adquirido de La Hidráulica Mexicana, la toma de agua del río Grande para aprovecharla en Atequiza como fuerza motriz, y la que se hizo para elevar el agua del lago de Chapala para riegos. ${ }^{84}$

Tras varias desavenencias, parecían haber llegado a un acuerdo provechoso para todas las partes involucradas; Bermejillo y Cuesta Gallardo ampliaban su poder y los García de Quevedo conservaban ciertos beneficios para alimentar sus tierras, al mismo tiempo que incursionaron en la gran hidráulica como ingenieros. Sin embargo, también hubo momentos tensos, particularmente cuando Cuesta Gallardo puso en marcha un nuevo proyecto de desecación de la ciénega de Chapala.

\section{Segundo conflicto: mediación de los ingenieros-hacendados} con la Compañía Hidroeléctrica de Chapala

La boyante hacienda de Atequiza era regada por las aguas de la laguna de Cajititlán y del río Santiago. Su expansión territorial se dirigía hacia tierras aledañas al Lerma y a Chapala. Aprovechando la gubernatura de Jalisco, Manuel Cuesta Gallardo logró obtener de Porfirio Díaz el aprovechamiento agrícola de las cincuenta mil hectáreas de la ciénega de Chapala que quedarían exentas de los desbordes del lago. Se trató de una obra que realizó a través de su Compañía Agrícola de Chapala y que se llevó a cabo entre los años 1905 y 1910, lo que demandó la acción conjunta de los hacendados y las autoridades regionales.

La iniciativa de Cuesta Gallardo contó en un principio con la firme oposición de los hacendados ribereños de Chapala, conflicto en el que intervinieron activamente Manuel y Miguel Ángel García de Quevedo en 1906. Aunque no eran parte interesada directamente, se habían visto involucrados en el proceso desde años atrás debido a múltiples factores: como miembros de La Hidráulica, habían vendido la empresa a Cuesta

\footnotetext{
83 AGN, Caja de Préstamos, vol. 69, exp. 186, pp. 3-4.

84 AHJ, IP, Manuel F. Chávez, t. 6, 15 de diciembre de 1903, ff. 5-5v.
} 
Gallardo; Manuel había trabajado para Cuesta Gallardo y tenía un trato de concesión eléctrica y Miguel había apoyado a Cuesta Gallardo, desde 1900, a "inclinar a los propietarios ribereños, mis clientes y amigos, a cooperar en todo lo referente a la irrigación, mas nunca, por ningún motivo, a intentar cosa alguna contra sus derechos e intereses de propietarios ribereños". 85

Las intenciones de desecación de Cuesta Gallardo, que faltaban "así a la ley económica y social que rige toda empresa realmente benéfica, todo orden y progreso: el respecto al derecho de otros", ${ }^{86}$ y las quejas de los vecinos motivaron que el gobierno comisionara a Miguel para emitir su opinión sobre el tema, lo que realizó desde una perspectiva tecnocientífica, situándose, desde el principio, en un punto neutral. ${ }^{87}$

Según él, el quid de la cuestión radicaba en qué se entendía por el límite del lago de Chapala para permitir la desecación de la zona. Los estudios realizados por su hermano Manuel ${ }^{88}$ y Marroquín y Rivera en 1903 habían considerado los límites de las aguas más altas, y lo conveniente habría sido el nivel medio del lago, para distinguir las aguas de propiedad federal y las de propiedad particular. Esa situación había provocado que los ribereños enviaran una carta a Manuel, el 28 de mayo de 1906, en la que indicaban que la curva era tan alta que "abarca la totalidad o gran parte de los terrenos de nuestras haciendas ribereñas de la laguna, terrenos que sólo han sido anegados eventualmente por muy corto periodo de tiempo en las más altas aguas, o del todo extraordinarias subidas de nivel de las aguas, nunca por las altas aguas ordinarias". Era un límite que les perjudicaba porque tales terrenos serían considerados de la na-

85

86

87

(19s

\footnotetext{
.

misionó a los ingenieros Don Manuel Marroquín y Rivera y Don Manuel G. de Quevedo para que pasaran unidos a la laguna y procedieran a trazar la curva de sus más "altas aguas", señalando los puntos de dicha curva por medio de monumentos adecuados que en todo tiempo "se reconozcan", recomendándoles informaran "sobre el resultado de su comisión con todo el detalle necesario, indicando el modelo empleado en la construcción de los monumentos y los procedimientos requeridos para el trazo, así como los datos que hayan tenido a la vista" y remitieran un plano de la misma curva. El resultado fue el "Informe relativo a los niveles alcanzados por la Laguna de Chapala en sus altas aguas, durante el siglo pasado", en el cual dan los datos recogidos por Manuel G. de Quevedo, el 31 de marzo de 1904. Quevedo, La cuestión del lago de Chapala, p. 10.
} 
ción, y le preguntaban cuál era la cota de las aguas ordinarias, lo que les fue informado. ${ }^{89}$ Tras una ardua negociación, Cuesta Gallardo obtuvo la concesión.

En el asunto, los Quevedo figuraron como mediadores en un conflicto jurisdiccional, una actividad para la que los actores involucrados les consideraban capacitados en función de su profesión de ingenieros. Pero en medio había otros intereses que debían ser aclarados para evitar caer en subjetivismos que eliminaran la racionalidad de sus actividades profesionales y que se derivaban de las relaciones laborales y personales con los ribereños afectados por Cuesta Gallardo. Esto les puso en una situación comprometida por varios motivos, principalmente el compromiso moral para apoyar a los ribereños en las obras de irrigación; el compromiso legal emanado de los contratos de irrigación y el tecnológico adquirido para asesorar y realizar obras de irrigación para los ribereños y para Cuesta Gallardo.

Con las adquisiciones a los Quevedo, los intereses de la poderosa familia Cuesta Gallardo, a la que unían vínculos de compadrazgo con el presidente Porfirio Díaz, confluyeron con los de la familia Martínez Negrete Bermejillo, propietaria de las haciendas de Buena Vista y de Jesús María, así como de la hidroeléctrica del Salto y la fábrica de Río Grande, que presionaba para la obtención de mayor corriente eléctrica.

Estas dos familias se unieron a otros empresarios nacionales y extranjeros para fundar la Compañía Hidroeléctrica e Irrigadora del Chapala, una sociedad anónima por acciones que concentró abundante capital. Contó con capitalistas de Guadalajara y de México, empresarios individuales y compañías industriales, comerciales y bancarias. ${ }^{90}$ Entre ellos, desde luego, no estaba la familia Quevedo, al menos originalmente; a la postre, uno de los hijos de Manuel, el abogado Valente García de Quevedo, con quien compartió mesa directiva de la Cámara Agrícola Jalisciense, se convirtió en el representante legal de la Irrigadora.

Finalmente, en 1909, cuando se configuró oficialmente la Compañía Hidroeléctrica e Irrigadora del Chapala, se celebró un contrato con el gobierno de Jalisco en el que se unificaron diversos contratos previos realizados con particulares y empresas que habían sido incorporadas a la

89

90 Era una gran empresa industrial que mantenía una separación entre los propietarios de las acciones (capitalistas) y los gerentes o el consejo directivo. Se organizó de manera estratificada y diversificada, ofreciendo el suministro de energía eléctrica y el servicio de transporte de tranvías eléctricos. Valerio, "Empresas, tranvías y alumbrado público", p. 237. 
Hidroeléctrica. ${ }^{91}$ Por ejemplo, su principal accionista, Manuel Cuesta Gallardo, aportó entre otras cosas la compra realizada a la Hidráulica Mexicana, así como la concesión que obtuvo del gobierno federal para explotar y desecar los terrenos de la ciénega de Chapala. ${ }^{92}$ En el contrato se autorizaba a la Hidroeléctrica a que facilitara energía eléctrica para cualquier uso que se le quisiera dar en los municipios de Guadalajara, San Pedro Tlaquepaque y Zapopan. ${ }^{93}$ Poco habría de durar el triunfo de Cuesta Gallardo, pues con la revolución las tierras fueron repartidas y el uso de la moderna tecnología para el acaparamiento de tierras llegó a su fin.

\section{Conclusión}

Así, a través de las líneas precedentes se ha podido observar cómo la transición de la pequeña a la gran hidráulica dio oportunidad de desarrollar las mejores capacidades de los ingenieros-hacendados; también permitió diversificar actividades y reforzar los vínculos tradicionales a través de relaciones económicas, sumados a los vínculos modernos de estas elites, en los que se manifestaban el prestigio personal y profesional. El trato cercano con sus vecinos y su capacidad profesional inspiraban un respeto por los ingenieros que éstos emplearon como capital simbólico para continuar el proceso de modernización que se estaba desarrollando en la ciudad y en otras partes del país y en el que la "domesticación" del agua era crucial.

Es importante mencionar que estos personajes tenían vínculos tradicionales entre sí y también con el gobierno central. Formaban parte al mismo tiempo del aparato burocrático de Díaz encaminado al control del agua y al incremento de la producción agrícola a través del otorgamiento de concesiones a grandes propietarios.

91 Se reconocía a la Compañía Hidroeléctrica e Irrigadora del Chapala como sucesora de la Nueva Compañía de Tranvías, Luz y Fuerza de Guadalajara. Valerio, "Empresas, tranvías y alumbrado público", p. 253. AHJ, Material de 1915. Sobre la marcha de las diversas concesiones de que han disfrutado las compañías La Electra S.A. y La Cía. Hidroeléctrica e Irrigadora del Chapala. Valerio, "Empresas, tranvías y alumbrado público", p. 254. Fue un contrato exclusivo por cincuenta años, según el cual debía conservar en buen estado sus plantas eléctricas, la maquinaria de reserva que fuera necesaria para asegurar el servicio de alumbrado público, el de abastecimiento de fuerza motriz a las bombas de los Colomos -origen del agua potable de Guadalajara- y el servicio de tranvías eléctricos. También debía cambiar el cableado aéreo por subterráneo en las calles del centro de la ciudad. Valerio, "Empresas, tranvías y alumbrado público", p. 254. 
No obstante, cabe destacar una situación particular. Kroeber ${ }^{94}$ sostiene que los ingenieros de campo -enviados por el gobierno central para mediar entre los propietarios y hacer los estudios de campo pertinentes para las obras de irrigación propuestas- no tenían el suficiente conocimiento de la zona, del historial de lluvia de por lo menos cincuenta años, de los suelos, de las estructuras geológicas y de los asentamientos humanos que les permitieran hacer propuestas para un mejor uso del agua y enriquecimiento de la agricultura. Por lo que se ha podido ver, no fue ése el caso de los García de Quevedo, pues ellos mismos eran propietarios de una de las hacienda involucradas en el proceso, su familia había sido propietaria de otra de las haciendas afectadas y habían llevado a cabo obras de irrigación en diversas fincas aledañas, de ahí los clientes que se mencionan. Eran personajes que desde su práctica profesional privada habían enriquecido su conocimiento local y lo pusieron al servicio del gobierno para mediar en el conflicto entre sus pares, los otros hacendados y Manuel Cuesta Gallardo. Fue así que a la pericia del conocimiento nuevo, el tecnológico, adquirido en México y en Francia por ambos hermanos y que les valió para medir el flujo del río, la altura del agua y la propuesta de proyectos novedosos, se sumaba el conocimiento heredado, certero, del terreno y de las personas involucradas en el proceso y las redes clientelares. Eran, efectivamente, los antecesores de los "hidrócratas", pero con características peculiares que parecen ser obviadas por autores como Wester, debido a su conexión íntima con el lugar que estudiaban y explotaban, lo que se consigue observar a través de la reducción de la escala y la comprensión de los procesos micro y macro que se llevaban a cabo simultáneamente.

Por último, señalemos un tema que deberá ser abordado en un futuro: cabría preguntarse qué pasó con los pequeños propietarios y las comunidades; por qué no figuraron en el conflicto ni en los documentos de los ingenieros; seguramente fueron desplazados por los intereses de los grandes propietarios que eran el foco de atención del gobierno porfirista.

\section{Siglas}

AHJ Archivo Histórico de Jalisco

AHIP Archivo Histórico de Instrumentos Públicos del Estado de Jalisco AHA Archivo Histórico del Agua AGN Archivo General de la Nación

94 $\quad$ Kroeber, Man, Land and Water, p. 234. 


\section{Fuentes}

Aboites Aguilar, Luis y Valeria Estrada (comp.)

Del agua municipal al agua nacional. Materiales para una historia de los municipios en México 1902-1945, México, Archivo Histórico del Agua, 2004.

Aboites Aguilar, Luis

El agua de la nación. Una historia política de México, 1888-1946, México, Centro de Investigaciones y Estudios Superiores en Antropología Social, 1998.

Aguilar Soto, César

"Empresarios agrícolas y conflictos por el agua en Sinaloa, 18961930", Clío, Nueva época, vol. 4, núm. 32, 2004, pp. 73-92.

Alamán, Lucas

Diccionario universal de historia y geografía, México, 1853.

Aldana, Mario

Desarrollo económico de Jalisco, 1821-1940, Guadalajara, Universidad de Guadalajara, 1979.

Alejandre Alejo, Julio

Participación jalisciense en las exposiciones de finales del siglo XIX, tesis de licenciatura, Universidad de Guadalajara, 2009.

Birrichaga Gardida, Diana

"Legislación en torno al agua, siglos XIX y XX", en Semblanza histórica del agua en México, México, Secretaría del Medio Ambiente y Recursos Naturales, 2009, pp. 43-59.

Boehm de Lameiras, Brigitte

"Arrendatarios y prestamistas en la ciénega de Chapala durante el porfiriato", Relaciones, año XI, núm. 43, 1990, pp. 7-37.

Boehm de Lameiras, Brigitte

"La desecación de la ciénega de Chapala y las comunidades indígenas: el triunfo de la modernización en la época porfiriana", en Sistemas hidráulicos, modernización de la agricultura y migración, Toluca, El Colegio Mexiquense, Universidad Iberoamericana, 1994, pp. 339-384.

Boehm de Lameiras, Brigitte

"Guadalajara y Chapala: historia de una relación regional. Siglo XIX y principios del Xx", en R. Ávila Palafox, El Occidente de México en el tiempo, Guadalajara, Universidad de Guadalajara, 1994, pp. 135-158.

Boehm de Lameiras, Brigitte

"La problemática agrohidráulica del lago de Chapala y su región", Encuentro, año I, núm. 1, 1982, pp. 101-119. 
Boehm de Lameiras, Brigitte

"Características hidrológicas e historia hidráulica de la ciénega de Chapala", en P. Ávila García (coord.), Agua, cultura y sociedad en México, Zamora, El Colegio de Michoacán, Instituto Mexicano de Tecnología del Agua, 2002, pp. 89-102.

Boehm de Lameiras, Brigitte

"Historias del agua en zonas de alta inversión para el desarrollo en el Centro Occidente de México", en El agua en la Historia de México, Zamora, El Colegio de Michoacán, Universidad de Guadalajara, 2005, p. 34-35.

Boehm de Lameiras, Brigitte, Juan Manuel Durán Juárez y Martín Sánchez Rodríguez (coord.),

Los estudios del agua en la cuenca Lerma-Chapala-Santiago, Zamora, El Colegio de Michoacán, Universidad de Guadalajara, 2002.

Boehm de Lameiras, Brigitte

"Transformación del paisaje industrial y urbano en el Occidente de México: los proyectos de la familia Cuesta Gallardo durante el porfiriato", ponencia presentada en el 51ํㅡㄹ Congreso Internacional de Americanistas en Santiago de Chile del 14 al 19 de julio de 2003.

Carmona, Juan, "Aristocratie foncière et progrès agricole en Espagne au XIXe siècle", en Nadine Vivier (dir.), Élites et progrès agricole. XVI-XX siècle, Rennes, Presses Universitaires de Rennes, 2009, pp. 259-277.

Castañeda González, Rocío

Las aguas de Atlixco. Estado, haciendas, fábricas y pueblos, 18801920, México, El Colegio de México, Archivo Histórico del Agua, 2006.

Colección de los decretos, circulares y órdenes de los poderes legislativo y ejecutivo del estado de Jalisco, Guadalajara, Tip. de I. Banda, t. 16, 1897. Compañía Anónima de Navegación y Comercio sobre El Lago de Chapala y Río Grande, Guadalajara, Imprenta de P. González, 1866.

Durand, Jorge

Los obreros de Río Grande, Zamora, El Colegio de Michoacán, 1986.

Escobar Ohmstede, Antonio

"El oriente de San Luis Potosí visto a través de la conflictividad del agua y la tierra, ¿ciclos que se abrieron?", en Mexico in Transition: New Perspectives on Mexican Agrarian History, Nineteenth and Twentieth Centuries, México, Centro de Investigaciones y Estudios Superiores en Antropología Social, 2013.

García Corzo, Rebeca V.

Biografía del ingeniero jalisciense Manuel García de Quevedo y Zubieta (1854-1924), tesis de doctorado en Historia y Análisis Social. Métodos y Análisis socio-cultural, Universidad de Oviedo, 2010. 
García de Quevedo, Manuel

"Conferencia popular sobre irrigación", en Boletín de la Sociedad de Ingenieros de Jalisco, 1902.

García de Quevedo, Manuel

"Segunda conferencia sobre irrigación", en Boletín de la Escuela de Ingenieros de Jalisco, t. I, núm. 8, 1902.

Garza, Enrique de la

"La integración de la industria eléctrica en México", en P. Arias (coord.), Industria y Estado en México, Zamora, El Colegio de Michoacán, 1990.

Gibbon, Edward

Guadalajara: la Florencia mexicana, vagancias y recuerdos: el salto de Juanacatlán y el Mar Chapálico, Guadalajara, Imprenta del Diario de Jalisco, 1893.

Hérin, Robert

"Consideraciones sobre la valoración social del agua", Investigaciones Geográficas, núm. 31, 2003.

Iguíniz, Juan Bautista

Guadalajara a través de los tiempos. Relatos y descripciones desde el siglo XVI hasta nuestros días, Guadalajara, Ayuntamiento de Guadalajara, t. II, 1989.

Kroeber, Clifton B.

Man, land and water: Mexico's farmlands irrigation policies. 18851911, Berkeley, 1983.

Leferme-Falguières, Frédérique y V. Van Renterghem

"Le concept d'élites. Approches historiographiques et méthodologiques", Hypothèses, núm, 1, 2000, pp. 55-67.

Legislación federal complementaria del Derecho civil mexicano, colección formada por José Vázquez Tagle y otros (1897- 1898), México, Tipografía Artística de Ramón F. Riveroll.

Lizama Silva, Gladys

"Francisco Martínez Negrete Alba, 1848-1906, ¿un empresario moderno?", en María Guadalupe Rodríguez López (coord.), La nostalgia y la modernidad. Empresarios y empresas regionales de México. Siglos XIX y XX, Durango, Universidad Juárez del Estado de Durango, 2006, pp. 353-386.

Matute, Juan Bautista

Proyecto de canalización de una parte del río Grande, Guadalajara, 1871.

Molina Enríquez, Andrés

Los grandes problemas nacionales, México, Imp. de A. Carranza e Hijos, 1906. 
Oñate, Abdiel

Banqueros y hacendados. La quimera de la modernización, México, Universidad Autónoma Metropolitana-Xochimilco, 1991.

Quevedo, Miguel Ángel de

La Cuestión del lago de Chapala. Dictamen presentado al Sr. Ministro de Fomento sobre el Aprovechamiento de las aguas del lago, México, Talleres de P. Rodríguez, 1906.

Robert, J.

"Las aguas arquetípicas y la globalización del desvalor", en P. Ávila García, (ed.), Agua, cultura y sociedad en México, Zamora, El Colegio de Michoacán, Instituto Mexicano de Tecnología del Agua, 2002.

Romero Navarrete, Lourdes

El río Nazas y los derechos de agua en México: conflicto y negociación en torno a la democracia, 1878-1939, México, Centro de Investigaciones y Estudios Superiores en Antropología Social, Universidad Autónoma de Coahuila, 2007.

Sánchez Rodríguez, Martín

"De la tradición a la modernidad. Cambios técnicos y tecnológicos en los usos del agua", en Semblanza histórica del agua en México, México, Secretaría del Medio Ambiente y Recursos Naturales, 2009, pp. 27-42.

Sánchez Rodríguez, Martín

"La herencia del pasado. La centralización de los recursos acuíferos de México", Relaciones, XIV, núm. 54, 1993, pp. 21-41.

Santacruz León, Germán

"Conflictos sociales por el uso del agua en la cuenca del río Valles, Huasteca, México (1900-1945)", Revista del Colegio de San Luis, Nueva época, año 11, núm. 4, jul.-dic. 2012, pp. 100-129.

Sarrazin, François

Les élites agricoles et rurales, Rennes, Presses Universitaires de Rennes, 2014.

Sarrazin, François

"Introduction", en Nadine Vivier (dir.), Élites et progrès agricole. XVIXX siècle, Rennes, Presses Universitaires de Rennes, 2009, pp. 9-18.

Suárez Cortez, Blanca Estela (coord.)

Historia de los usos del agua en México. Oligarquías, empresas y ayuntamientos (1840-1940), México, Centro de Investigaciones y Estudios Superiores en Antropología Social, Instituto Mexicano de Tecnología del Agua, 1998.

Suárez Cortez, Blanca Estela y Diana Birrichaga Gardida

Dos estudios sobre usos del agua en México (siglos XIX y XX), México, 
Centro de Investigaciones y Estudios Superiores en Antropología Social, Instituto Mexicano de Tecnología del Agua, 1997.

Tolentino, Francisco

"Memorias de Gobierno (1883-1887)", en Aída Urzúa Orozco y Gilberto Hernández Z. (comp.), Jalisco. Testimonio de sus gobernantes, Guadalajara, Universidad Nacional de Educación a Distancia, Gobierno de Jalisco, 1988, t. II, pp. 23-137.

Tortolero Villaseñor, Alejandro

De la coa a la máquina de vapor. Actividad agrícola e innovación tecnológica en las haciendas mexicanas, 1880-1914, México, Siglo XXI, 1995.

Tortolero Villaseñor, Alejandro

El agua y su historia: México y sus desafíos hacia el siglo XXI, México, Siglo XXI, 2000.

Tortolero Villaseñor, Alejandro

"Les grandes exploitations mexicaines au coeur du changement agricole? Routine ou innovation agraires: les élites de Chalco au XIXe siècle", en Nadine Vivier (dir.), Élites et progrès agricole XVI-XX siècles, Rennes, Presses Universitaires de Rennes, 2009, pp. 227-254.

Tortolero Villaseñor, Alejandro

Notarios y agricultores. Crecimiento y atraso en el campo mexicano, 1780-1920, México, Universidad Autónoma de México, Siglo XXI, 2008.

Tortolero Villaseñor, Alejandro

Tierra, agua y bosques. Historia y medio ambiente en el México central, México, Centre Français d'Études Mexicaines et Centraméricaines, 1996.

Valerio Ulloa, Sergio

"Empresas, tranvías y alumbrado público. La Compañía Hidroeléctrica e Irrigadora del Chapala", en María Eugenia Romero Ibarra et al., Poder público y poder privado: gobierno, empresarios y empresas, 1880-1980, México, Universidad Nacional Autónoma de México, 2006, pp. 233-292.

Valerio Ulloa, Sergio

Historia rural jalisciense. Economía agrícola e innovación tecnológica durante el siglo XIX, Guadalajara, Universidad de Guadalajara, 2003.

Ventura Rodríguez, María Teresa, S.F. Rosas Salas y S.R. Jiménez (coord.) El agua en las regiones: miradas históricas y perspectivas contemporáneas, Puebla, Benemérita Universidad Autónoma de Puebla-Instituto de Ciencias Sociales y Humanidades "Alfonso Vélez Pliego", 2013.

Vivier, Nadine

"Élites et progrès agricole, XVIe-XXe siècles, Rennes, Presses Universitaires de Rennes, 2009. 
Vivier, Nadine

"Quelles élites pour l'agriculture française au xixème siècle?". http:// www.academie-agriculture.fr/seances/quelles-elites-pour-lagriculture.

Von Mentz, Brígida y R. Marcela Pérez López (comp.)

Manantiales, ríos, pueblos y haciendas. Dos documentos sobre conflictos por aguas en Oaxtepec y en el Valle de Cuernavaca (1795-1807), México, Centro de Investigaciones y Estudios Superiores en Antropología Social, Instituto Mexicano de Tecnología del Agua, 1998.

Weiner, $\mathrm{R}$.

"El declive económico de México en el siglo XIX: una perspectiva cultural”, Signos Históricos, núm. 12, 2004.

Wester, Phillippus

"Capturing the Waters: the Hydraulic Mission in the Lerma-Chapala Basin, Mexico (1876-1976)", Water History, núm. 1, 2009, pp. 9-29.

Wester, Phillippus

Shedding the Waters: Institutional Change and Water Control in the Lerma-Chapala Basin, Mexico, Wageningen Agricultural University (Países Bajos), 2009. 